\title{
Modeling Applied in Prediction and Allocation of Water Resources in Vast Area
}

\author{
Sunyechu Wang \\ School of Mathematics \& Computational Science \\ Sun Yat-sen University \\ Guangzhou, China \\ e-mail: sophiawatson@163.com
}

\author{
Jieting Gong \\ School of Mathematics \& Computational Science \\ Sun Yat-sen University \\ Guangzhou, China \\ e-mail: satanfever@163.com
}

\author{
Kaixi Huang \\ School of Mathematics \& Computational Science \\ Sun Yat-sen University \\ Guangzhou, China \\ e-mail: hkxi@qq.com
}

\begin{abstract}
Thepaper mainly discusses prediction of water consumption and precipitation and allocation among areas. First of all, the vast area is divided into smaller parts according to its water resources, measured by precipitation in recent years. Precipitation and water consumption is predicted within each part before deciding water transportation plan among areas.
\end{abstract}

Keywords: GM(1,1) model, Gray-Markov Chain model, linear programming, unbalanced transportation problem

\section{PREDICTION OF WATER RESOURCES}

We first divided the vast area into smaller parts according to its water resources, measured by precipitation in recent years. Water consumption and precipitation in former years are analyzed within those smaller areas and prediction of their future volume is made. $\operatorname{GM}(1,1)$ model is adopted in prediction of water consumption. But it yields little fruit in predicting precipitation for precipitation fluctuates fiercely as time goes by. Deviation still exists when we ameliorate the model with unbiased GM $(1,1)$ model. Finally the introduction of Markov chain is adopted to help gain an accurate result.

Allocation of water among areas is turn into an unbalanced transportation problem. We further turn the unbalanced problem into a balanced one by setting a visual consumer. Then linear programming aiming at minimum cost is adopted to solve the problem.

\section{A. Prediction Of Water Consumption}

Here we take mainland China as an example. Based on precipitation, we divided the area into ten parts.(see Fig. 1)

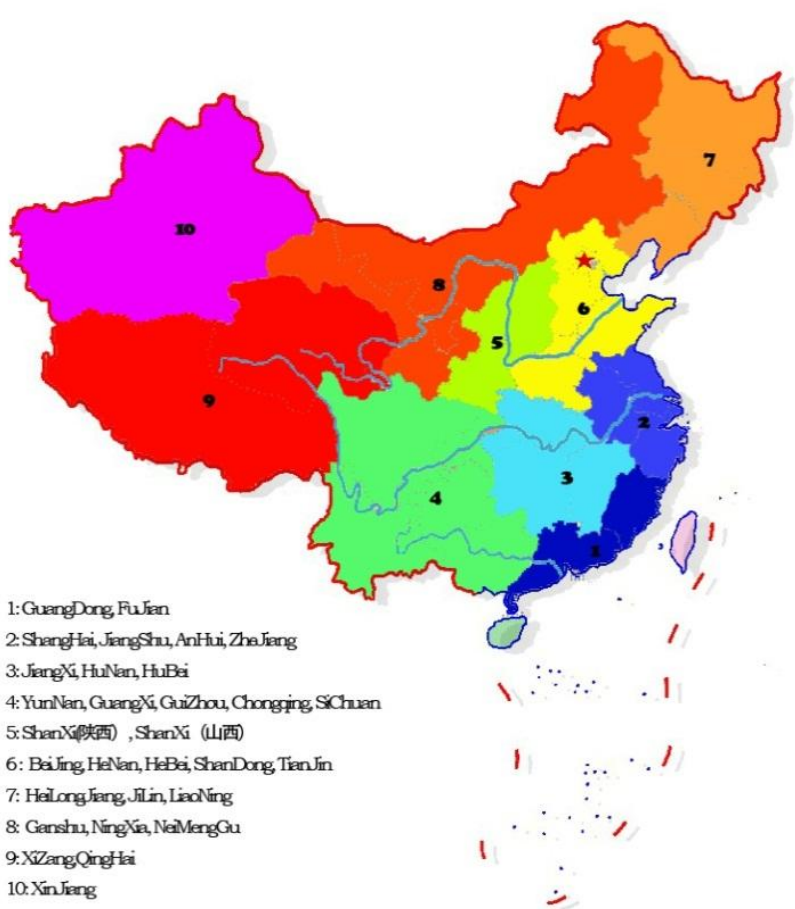

Figure 1.

Under such division, water consumption from 2003 to 2010 within each part is presented as below.(see Table I)

\begin{tabular}{ccccccccc}
\multicolumn{7}{c}{ TABLE I } \\
\hline ZoneYear & 2003 & 2004 & 2005 & 2006 & 2007 & 2008 & 2009 & 2010 \\
\hline $\mathbf{1}$ & 640.3 & 649.73 & 645.81 & 646.65 & 658.79 & 659.57 & 664.85 & 671.46 \\
\hline 2 & 927.1 & 1061.3 & 1058.9 & 1115.1 & 1121.6 & 1161.1 & 1164.1 & 1174.6 \\
\hline 3 & 736.4 & 769.82 & 789.87 & 792.2 & 817.86 & 828.54 & 844.99 & 852.91 \\
\hline 4 & 791.3 & 809.85 & 840.36 & 847.5 & 849.88 & 855.53 & 865.14 & 867.16 \\
\hline $\mathbf{5}$ & 131.3 & 131.42 & 134.48 & 144.09 & 140.29 & 142.38 & 140.61 & 147.18 \\
\hline 6 & 662.3 & 668.06 & 668.18 & 714.06 & 689.51 & 699.85 & 706.29 & 698.45 \\
\hline 7 & 478.1 & 488.86 & 624.44 & 530.35 & 535.02 & 543.87 & 570.13 & 588.71 \\
\hline 8 & 352.5 & 367.29 & 375.82 & 378.65 & 373.54 & 372.13 & 374.11 & 376.09 \\
\hline 9 & 54.3 & 58.16 & 63.84 & 67.23 & 67.81 & 71.89 & 59.61 & 65.97 \\
\hline 10 & 500.7 & 497.06 & 464.36 & 513.43 & 517.74 & 528.22 & 530.9 & 535.08 \\
\hline
\end{tabular}

Let's present the data in columnar section(see Fig. 2). 
Conclusion could be drawn that water consumption varies slightly as time goes by.

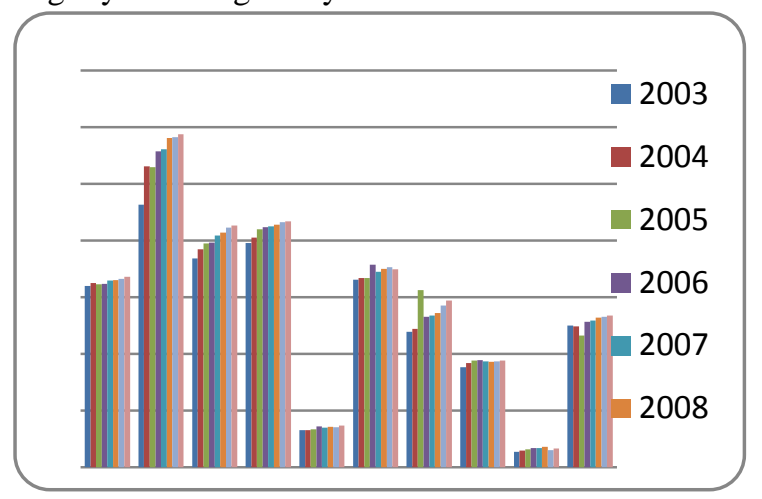

Figure 1.

For further prediction, variation of water consumption is needed. Here we adopt $\operatorname{GM}(1,1)$ model to achieve the goal.

First, E0 (the origin sequence) is as below.

$$
E_{0}=(E(1), E(2), \ldots, E(n))
$$

E1 is gained after accumulated generating operation

$$
E 1=(E 1(1), E 1(2), \ldots, E 1(n))
$$

in which

$$
E 1(k)=\sum_{i=1}^{k} E O(k), k=1,2, \ldots, n
$$

Then back ground value array $\mathrm{Z}$ is constructed according to E0

$$
Z=(z(2), z(3), \ldots, z(n))
$$

in which

$$
z(k)=\alpha(E 1(k)+E 1(k-1))(\text { in most cases } \alpha=0.5)
$$

As a result, we have

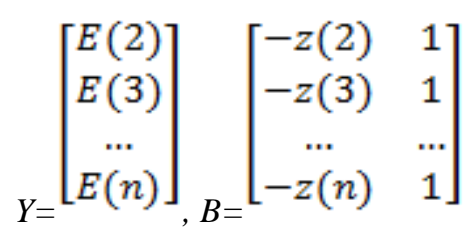

After least square estimation of parameter sequence, we have

$$
\hat{a}=[a, b]^{T}=\left(B^{T} B\right)^{-1} B^{T} Y .
$$

Then model can be decided and estimation of E0 computed.

$$
\begin{gathered}
E_{1}(\hat{k}+1)=\left(T(1)-\frac{b}{a}\right) e^{-a k}+\frac{b}{a}, k=1,2, \cdots n \\
\hat{E}(k)=\hat{E}_{1}(k)-\hat{E}_{1}(k-1)
\end{gathered}
$$

Error checking is needed at last. The residual is presented as

$$
\frac{1}{n} \sum_{i=1}^{n}(\hat{E}(i)-E(i))
$$

According to the model and the data, the outcome is presented as below(see Fig. 3).

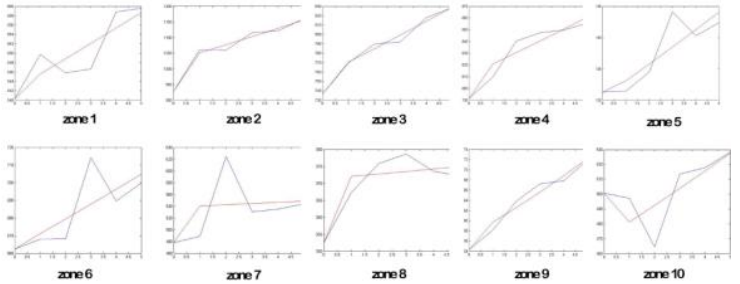

Figure 2.

It is learned that variation of water consumption could be highly stimulated by the model except abnormal data from a few years. So we can reasonably predict perspective water consumption in 2015,2020, 2025 within each part.(see Table.II)

\begin{tabular}{cccc}
\multicolumn{4}{c}{ TABLE II } \\
\hline Zone \Year & 2015 & 2020 & 2025 \\
\hline 1 & 690.78 & 713.02 & 735.97 \\
2 & 1304.5 & 1433.71 & 1575.72 \\
3 & 934.35 & 1019.04 & 1111.41 \\
\hline 4 & 915.55 & 960.65 & 1007.97 \\
\hline 5 & 157.4 & 169.35 & 182.22 \\
\hline 6 & 736.74 & 766.18 & 796.8 \\
7 & 615.96 & 657.94 & 702.79 \\
\hline 8 & 378.66 & 382.64 & 384.65 \\
\hline 9 & 70.55 & 74.32 & 78.28 \\
\hline 10 & 592.32 & 648.77 & 710.59 \\
\hline
\end{tabular}

We notice certain degree of growth in water consumption, but with no noticeable fluctuation. Therefore, the result is reliable.

\section{B. Prediction Of Precipitation}

Since large amount of data is needed, here we take Nanjing as an example in case the data amount is guaranteed. Precipitation in each part could be predicted similarly. 


\section{1) $\operatorname{GM}(1,1)$}

Based on precipitation per year in Nanjing during 1971 to 2008 , prediction of precipitation using $\operatorname{GM}(1,1)$ is presented as below.

TABLE III

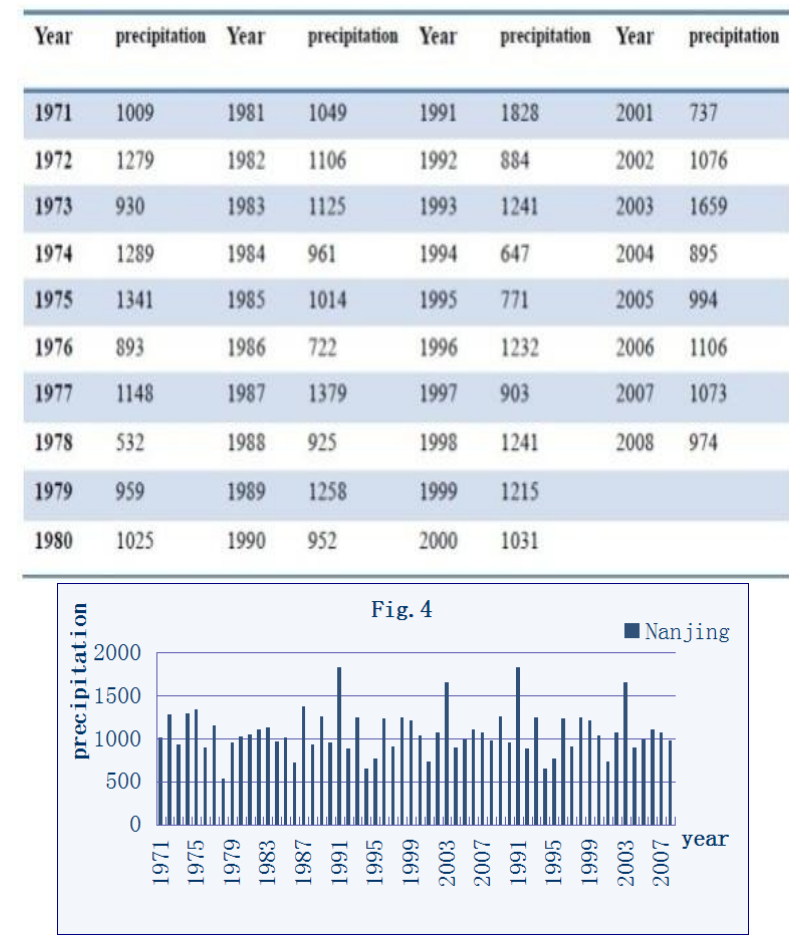

Figure 3.

We build the $\operatorname{GM}(1,1)$ model according to raw data in Table I. Then we have X(1) after accumulated generation operation of the sequence.

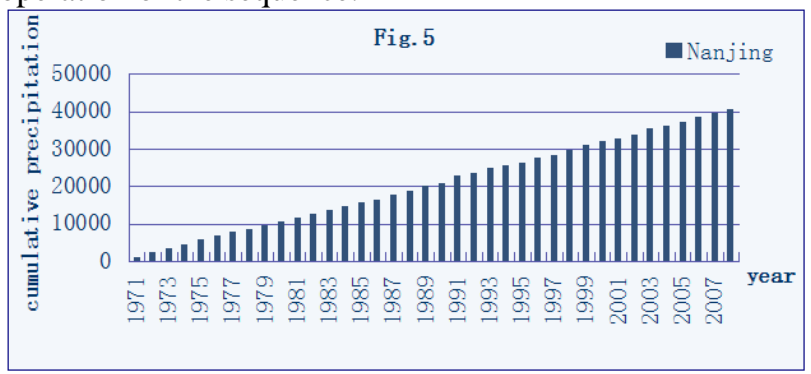

Figure 4.

Similar to $\operatorname{GM}(1,1)$ model adopted in prediction of water consumption, expression of the model could be computed in matlab as below:

$$
\hat{E}_{(k+1)}^{(0)}=1060.9 e^{0.000186}
$$

Prediction is presented as below.

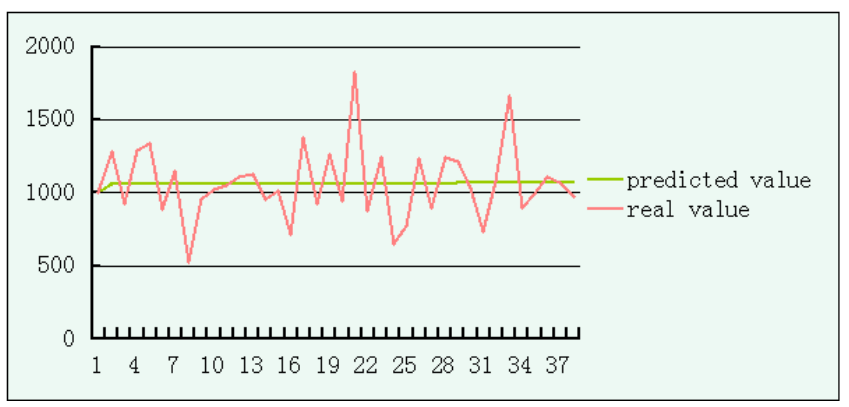

Figure 5.

TABLE IV

\begin{tabular}{|c|c|c|c|c|c|c|c|c|c|c|c|}
\hline Year & $\begin{array}{l}\text { predi- } \\
\text { cted } \\
\text { value } \\
\text { of GM }\end{array}$ & $\begin{array}{l}\text { relative } \\
\text { error }\end{array}$ & Year & $\begin{array}{l}\text { predi- } \\
\text { cted } \\
\text { value } \\
\text { of GM }\end{array}$ & $\begin{array}{l}\text { relative } \\
\text { error }\end{array}$ & Year & $\begin{array}{l}\text { predi- } \\
\text { cted } \\
\text { value } \\
\text { of GM }\end{array}$ & $\begin{array}{l}\text { relative } \\
\text { error }\end{array}$ & Year & $\begin{array}{l}\text { predi- } \\
\text { cted } \\
\text { value } \\
\text { of GM }\end{array}$ & $\begin{array}{l}\text { relative } \\
\text { error }\end{array}$ \\
\hline 1971 & 1009 & 0 & 1981 & 106292 & 0.01 & 1991 & 1064.90 & 0.42 & 2001 & 1066.89 & 0.45 \\
\hline 1972 & 1061.15 & 0.17 & 1982 & 1063.12 & 0.04 & 1992 & 1065.10 & 0.20 & 2002 & 1067.09 & 0.01 \\
\hline 1973 & 1061.34 & 0.14 & 1983 & 1063.32 & 0.05 & 1993 & 1065.30 & 0.14 & 2003 & 1067.29 & 0.36 \\
\hline 1974 & 1061.54 & 0.18 & 1984 & 1063.52 & 0.11 & 1994 & 1065.50 & 0.65 & 2004 & 1067.48 & 0.19 \\
\hline 1975 & 1061.74 & 0.21 & 1985 & 1063.71 & 0.05 & 1995 & 1065.71 & 0.38 & 2005 & 1067.68 & 0.07 \\
\hline 1976 & 1061.93 & 0.19 & 1986 & 1063.91 & 0.47 & 1996 & 1065.90 & 0.13 & 2006 & 1067.88 & 0.03 \\
\hline 1977 & 1062.13 & 0.07 & 1987 & 1064.11 & 0.23 & 1997 & 1066.09 & 0.18 & 2007 & 1068.08 & 0.00 \\
\hline 1978 & 1062.33 & 1.00 & 1988 & 1064.31 & 0.15 & 1998 & 1066.29 & 0.14 & 2008 & 1068.28 & 0.10 \\
\hline 1979 & 1062.53 & 0.11 & 1989 & 1064.51 & 0.15 & 1999 & 1066.49 & 0.12 & 2009 & 1068.48 & \\
\hline 1950 & 1062.72 & 0.04 & 1990 & 1064.71 & 0.12 & 2000 & 1066.69 & 0.03 & 2010 & & \\
\hline
\end{tabular}

Quite different from prediction of water consumption, precipitation is not effectively stimulated by the model for drought and flood could lead to abnormal data. To alleviate the impact of abnormal data, optimization with smoothing treatment is introduced into the model.

2) Optimized GM(1,1)

According to our optimization, we suggest that a sequence of $\mathrm{n}$ data is acquired.

$$
X^{(0)}=X^{(0)}(1), X^{(0)}(2), \ldots, X^{(0)}(n)
$$

Newly processed data could be expressed as:

$$
\begin{gathered}
X^{(0)}(t)=\frac{\left\{X^{(0)}(t-1)+2 X^{(0)}(t)+X^{(0)}(t+1)\right\}}{4} t \\
\in[2, n-1] \\
X^{(0)}(1)=\frac{\left(3 X^{(0)}(1)+X^{(0)}(2)\right)}{4} \\
X^{(0)}(n)=\frac{X^{(0)}(n-1)+3 X^{(0)}(n)}{4}
\end{gathered}
$$

And the expression of the ameliorated model is presented as below:

$$
\widehat{E}_{(k+1)}^{(0)}=1053.3 e^{0.00048}
$$




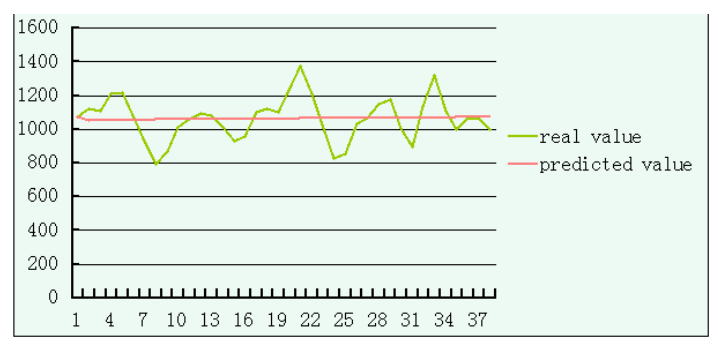

Figure 6.

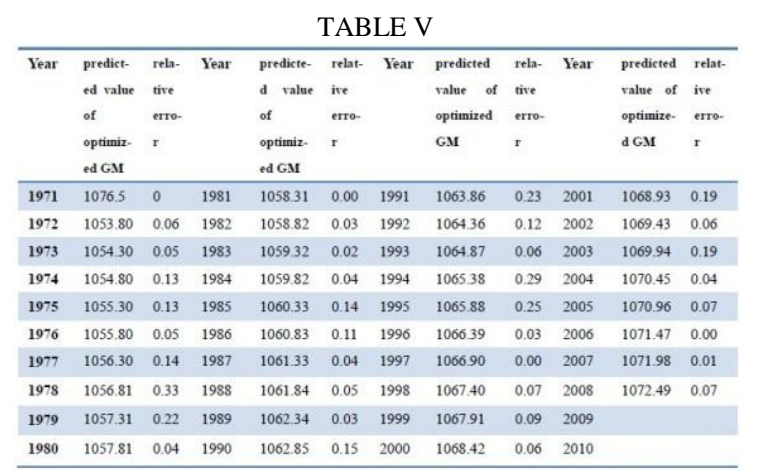

After comparison of the two models, we learn that relative error of the ameliorated model is smaller than the original one. However, deviation still exists. For a more accurate prediction, we build a new model combining advanced gray model stated above and Markov chain.

3) Optimized Grey-Markov Chain Model

Relative error of the advanced GM is analyzed and divided into 6 states as below

\begin{tabular}{lllllll}
\hline Error & $16-7$ & 74 & 4.0 & $0 \cdots 4$ & $4 \cdots 7$ & $9 \cdots 16$ \\
burst\% & & & & & & \\
\hline condition & 1 & 2 & 3 & 4 & 5 & 6 \\
\hline
\end{tabular}

According to the precipitation data, we have state matrix and single-step transition matrix.

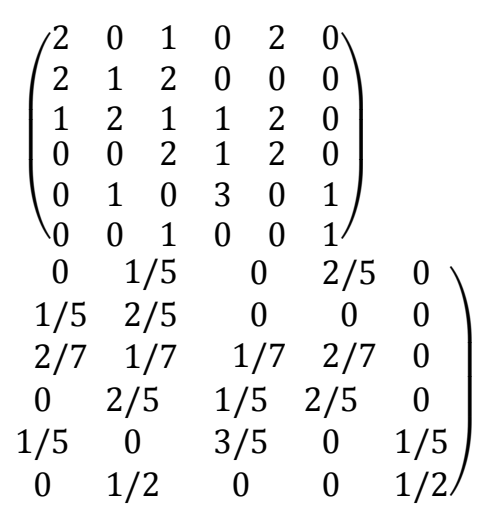

We decide the calculation formula based on the state of relative error of former year. For example, we predict the precipitation in 2008 to be 1071.98 whereas actually it was 974, then we indicate that precipitation in 2009 to be:

$1071.98+1 / 2 *(0.11 *(0.2)-0.04 *(0.6)-0.23 *(0.2)) * 974=$
1048.6

We witness only small deviation from the actual value after the precipitation is predicted. As a result, the prediction is well-rounded.

However, this model leaves something to be desired:

State division of relative error is decided arbitrary.

Influence of abnormal data is not perfectly eliminated.

\section{WATER Allocation AMONG SMALl AREAS}

Precipitation, $\mathrm{x}$ and water demand, $\mathrm{y}$ could be predicted by Gray-Markov model built above. We simply assume precipitation to be the only resource of water and it can be fully exploited. Water abundance is measured by $\mathrm{D}=\mathrm{x}-\mathrm{y}$. Water allocation among small areas is in fact an unbalanced transition problem. Those areas with $\mathrm{D}>0$ are decided as supplier while those with $\mathrm{D}<0$ are decided as consumer.

We suggest that water is transported via present river or pipeline so that cost for newly-built transportation will be zero. Transportation cost per distance is the same so overall transportation cost is proportional to distance between two areas. When the areas are big enough, we simply decide the distance to be linear distance.

Taking mainland China as example, we have cost matrix as below (based on division in Table.VI) :

\begin{tabular}{ccccccccccc}
\multicolumn{10}{c}{ TABLE VI } \\
\hline & 1 & 2 & 3 & 4 & 5 & 6 & 7 & 8 & 9 & 10 \\
\hline 1 & 0 & 1109 & 748.4 & 1608 & 1857 & 1802 & 3299 & 2522 & 3354 & 4380 \\
\hline 2 & 1109 & 0 & 831.6 & 1913 & 1220 & 803.8 & 2218 & 1774 & 3326 & 4075 \\
\hline 3 & 748.4 & 831.6 & 0 & 1137 & 1137 & 1220 & 2883 & 1802 & 2744 & 3687 \\
\hline 4 & 1608 & 1913 & 1137 & 0 & 1441 & 1968 & 3659 & 1940 & 1774 & 2938 \\
\hline 5 & 1857 & 1220 & 1137 & 1441 & 0 & 693 & 2245 & 665.2 & 2273 & 3493 \\
\hline 6 & 1802 & 803.8 & 1220 & 1968 & 693 & 0 & 1691 & 1053 & 2994 & 3493 \\
\hline 7 & 3299 & 2218 & 2883 & 3659 & 2245 & 1691 & 0 & 2051 & 4296 & 4380 \\
\hline 8 & 2522 & 1774 & 1802 & 1940 & 665.2 & 1053 & 2051 & 0 & 2245 & 2522 \\
\hline 9 & 3354 & 3326 & 2744 & 1774 & 2273 & 2994 & 4296 & 2245 & 0 & 1331 \\
\hline 10 & 4380 & 4075 & 3687 & 2938 & 3493 & 3493 & 4380 & 2522 & 1331 & 0 \\
\hline
\end{tabular}

Since overall precipitation overwhelms overall water consumption, a visual consumer is decided as $\mathrm{fm}$. $F m(X)=0, f m(y)=\sum x-\sum y$. Then unbalanced transportation is now turn into balanced transportation problem. In this model, water transported to fm represents water stored with in each area.

The transportation model we build is a black box. Input precipitation and water consumption and the model will automatically identify supplier and consumer as long as overall precipitation overwhelms overall water consumption. The optimal plan will computed aiming at minimum cost.

Input precipitation $x_{i}$ and $y_{i}$ in each area. $D_{i}=x_{i}-y_{i}$. $D_{i}$ is supply for suppler while $D_{i}$ is demand for consumer. Then the problem could be describe by linear equations as below

$$
\begin{gathered}
\text { sum }=\sum_{0<t r_{i j} \leq D_{i} t r_{i j} \leq y_{j}} \operatorname{cost}_{i j} * t r_{i j} \\
\operatorname{Min}(\text { sum) }
\end{gathered}
$$


In which const ${ }_{i j}$ presents transportation cost per distance from area $\mathrm{i}$ to area $\mathrm{j}$; $\operatorname{tr}_{\mathrm{ij}}$ represents transportation volume from area $i$ to area $j$.

The linear equations could be solved by linear programming.

We input precipitation and water consumption in 2008 to exam the model and the result is as below.

TABLE VII

\begin{tabular}{llllll}
\hline Area & 1 & 2 & 5 & 7 & 8 \\
\hline 3 & 133.89 & 142.39 & 266.77 & 404.99 & 104.71 \\
4 & 239.50 & 246.16 & 383.34 & 598.72 & 219.93 \\
6 & 435.13 & 246.16 & 508.43 & 118.51 & 381.66 \\
9 & 214.06 & 294.66 & 360.62 & 10.06 & 189.01 \\
10 & 61.81 & 41.19 & 233.10 & 80.95 & 10.73 \\
store & 40.42 & 57.37 & 177.61 & 76.51 & 10.96 \\
\hline
\end{tabular}

\section{REFERENCE}

[1] Feng $X$, China Academic Journal Electronic Publishing House, vol.18, No.6, Dec 2008, 'Supply Water Capacity Prediction Based on Mathematic Model', number: 1009-3907(2008)06-0049-02;

[2] Hongbin.L,Yong.Y, Suiningmeteorologic bureau, 'Rainfall Prediction in SuiningRegion Based on Grey-Markov Model';

[3] Jieming.ZH, China Academic Journal Electronic Publishing House,vol.18, No.4, 'Urban Supply Water Capacity Prediction Based on Multiple Linear Regressions';

[4] Zheng.Z, Jiayan $\cdot T$, Zhiming.L, China Academic Journal Electronic Publishing House vol.2 No.2 Apr.2008, 'The mathematic model of city water supply capacity', number: 1673-9353(2008)02-0011-05;

[5] Yuanjian.ZH, Jing. L, Long. WChina Academic Journal Electronic Publishing House vol.23, No.4, Oct 2009, 'Precipitation Predicting Model Based on Improved Markov Chain', number: 1671-3559(2009)04-0402-04 